\title{
The dynamics of heat lows in simple background flows
}

\author{
By T. SPENGLER ${ }^{1 *}$, M. J. REEDER ${ }^{2}$ and R. K. SMITH ${ }^{1}$ \\ ${ }^{1}$ Meteorologisches Institut der Universität München, Germany \\ ${ }^{2}$ Centre for Dynamical Meteorology and Oceanography, Monash University, Australia
}

(Received 8 December 2004; revised 3 May 2005)

\section{SUMMARY}

A three-dimensional numerical model is used to study the evolution of an idealized heat low that develops over an isolated level land mass surrounded by sea. Calculations are carried out without a background flow and for simple background flows. In all cases, the flow shows a significant diurnal variation in which the sea-breeze circulations are the prominent feature during the daytime and the nocturnal low-level jet is the prominent feature at night. If the land area is large enough so that the sea breezes do not cover it entirely during the diurnal cycle, strong convergence associated with the low-level jet leads to the formation of intense, but shallow, cold fronts along the inland boundaries of sea-breeze air. These fronts decay rapidly after sunrise when surface heating leads to renewed vertical mixing, which destroys the low-level stable layer.

The presence of a uniform easterly flow leads to the formation of a west-coast trough, similar to the situation commonly observed over Western Australia. The trough broadens during the day due to the heating of the land, while at night it sharpens and again frontogenesis occurs at low levels near the leading edge of the sea breezes to form shallow cold fronts. In these calculations there is an east-west asymmetry in the sea-breeze circulations: the cool air behind the west-coast sea breeze is shallower than that behind the east-coast sea breeze, but the vertical circulation associated with the west-coast sea breeze is deeper. The east-coast sea-breeze front penetrates further inland, but is more diffuse and is recognizable more by its signature in the relative vorticity than by that in the horizontal temperature gradient.

The presence of a horizontal shear-flow leads to the deformation of the heat trough, a process that appears to play an important role in the formation of cold fronts over central Australia. Again the calculations show the formation of shallow fronts over the land during the night, which frontolyse rapidly after sunrise. Despite the idealized nature of the calculations, the associated patterns of low-level vorticity, divergence and horizontal temperature gradient that develop overnight show remarkable similarity to those observed over central Australia. Indeed, the calculations help to interpret the observations of nocturnal frontogenesis over this region.

KEYWORDS: Deformation Frontogenesis Heat trough Inertial turning Low-level jet

\section{INTRODUCTION}

Heat lows and heat troughs are prominent features of the low-level atmospheric circulation over arid land regions in the subtropics, especially during the summer months where insolation is at its peak. Because of the dryness of the land, a large fraction of the incoming solar radiation is available to heat the surface as little is used to evaporate surface moisture.

Heat lows can have a strong effect on local weather. A good example is the 'westcoast trough' over Australia. The coastal areas of Western Australia can experience severe heat waves when the trough is offshore or milder conditions with an afternoon sea breeze when the trough is inland. This trough has been investigated using linear theories (Adams 1993) and idealized one- and two-level numerical models (Fandry and Leslie 1984; Kepert and Smith 1992). These studies show that, when the airstream is easterly and the land mass is heated, a trough develops on the west coast of the continent. Kepert and Smith (1992) suggest that orography plays a minor role in the formation of the trough, and that the trough position is influenced by cooling over the ocean. There are still issues concerning the predictability of the trough and its exact position (Leslie and Skinner 1994). While the work described in this paper has been motivated by observations acquired in the Australian subtropics, the processes are fundamental in nature and most likely operate in other regions of the world where heat

* Corresponding author: Institute for Atmospheric and Climate Science, Universitätsstr. 16 ETH Zentrum, CHN 8092 Zürich, Switzerland. e-mail: thomas.spengler@env.ethz.ch

(C) Royal Meteorological Society, 2005. 
lows are common. These regions include the Iberian Peninsula (Morris 1986; Gaertner et al. 1993; Alonso et al. 1994; Portela and Castro 1996; Serrano et al. 1999; Hoinka and Castro 2003), Saudi Arabia (Ackermann and Cox 1982; Blake et al. 1983; Smith 1986a,b; Bitan and Sa'aroni 1992), north Africa (Thorncroft and Flocas), south-west Africa (Pedgley 1972), Pakistan and north India (Joshi and Desai 1985), the QinghaiXizang plateau in China (Junning et al. 1986), and the south-western United States (Rowson and Colucci 1992; Douglas and Li 1996).

The present study builds on that by Rácz and Smith (1999, hereafter RS99). These authors examined the dynamics of the idealized heat low that forms in a numerical model in which there is diurnal heating and cooling of a square land mass surrounded by sea with a fixed sea surface temperature. They found that the heat low that forms has a strong diurnal cycle. The minimum surface pressure occurs in the late afternoon and the maximum occurs in the early morning, while the vertical component of relative vorticity is a minimum during the day and has a peak in the early morning. Moreover, the model develops a pronounced nocturnal low-level jet over the land. Interestingly, similar features are observed in cold fronts over central Australia (Smith and Ridley 1990; Smith et al. 1995; Deslandes et al. 1999; Reeder et al. 2000). The connection is that these fronts originate frequently from prefrontal troughs, which appear to result from the deformation of the heat low over Western Australia (Hanstrum et al. 1990b). The deformation is associated with the flow fields accompanying the approach of a cold front from the south-west towards the Australian continent. Hanstrum et al. (1990a) presented a climatology of these events and showed that they occur most commonly in spring (October). However, the heat trough itself is more pronounced in summer. The mobile heat troughs investigated by Hanstrum et al. (1990a) are probably more frequent in late winter and spring because the fronts then extend further equatorward, providing the necessary deformation to 'squeeze' the heat trough into a prefrontal tough.

Here we examine the effects of simple background flows on the dynamics of idealized heat lows using the same model as RS99. The aims of the work are: (i) to better understand how background flows, and especially those with horizontal shear, affect the structure and evolution of heat lows; and (ii) to clarify the relationship between heat troughs and the development of subtropical fronts. The remainder of the paper is structured as follows. To set the scene for the calculations to follow, we begin in section 2 with a summary of the low-level circulation over Australia. Section 3 summarizes the main features of the model. As a point of reference, calculations similar to those by RS99 in which there is no background flow are discussed in section 4. In sections 5 and 6 we investigate the effects of a uniform easterly flow and a horizontally sheared flow, respectively. The conclusions are presented in section 7 .

\section{LOW-LEVEL FLOW IN THE AUSTRALIAN REGION}

The key features of the mean low-level flow in the Australian region are summarized briefly as a point of contact between the idealized calculations and the real atmosphere. The summary is based on three-hourly forecasts valid at 0400 AEST and

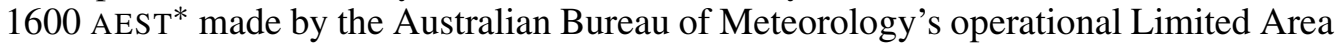
Prediction System, which is described by Puri et al. (1998).

Figures 1(a) and 1(b) show the 1600 AEST and 0400 AEST mean-sea-level pressure for the months of December, January and February (DJF) for the four years from 2000 to 2003 . The $925 \mathrm{hPa}$ mean wind and $925 \mathrm{hPa}$ mean ageostrophic wind at the same

\footnotetext{
* Australian Eastern Standard Time $=$ UTC $+10 \mathrm{~h}$.
} 
(a)

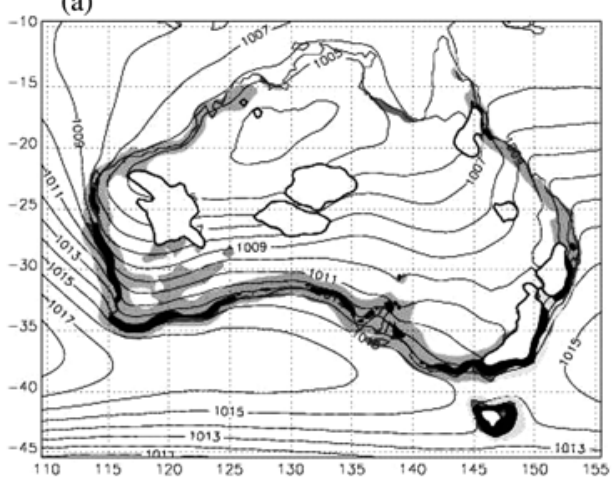

(c)

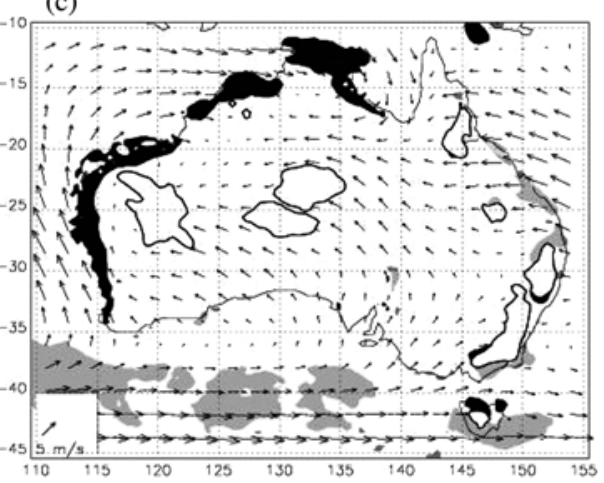

(e)

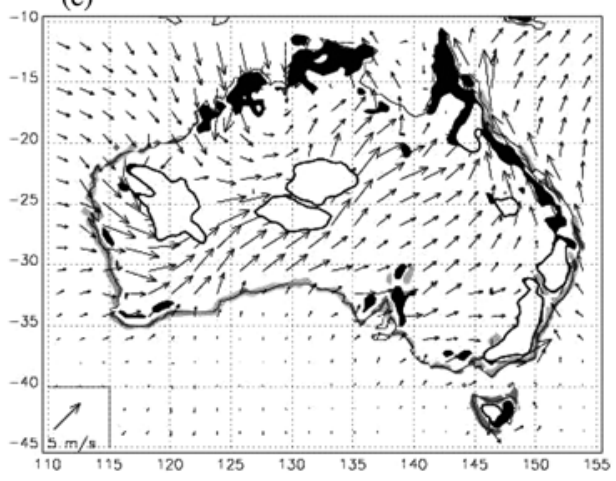

(b)

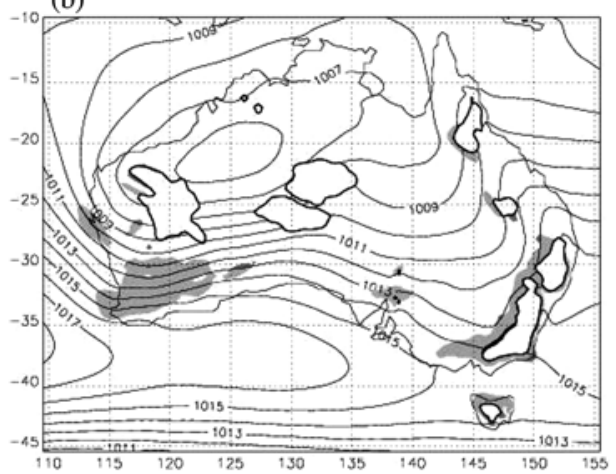

(d)

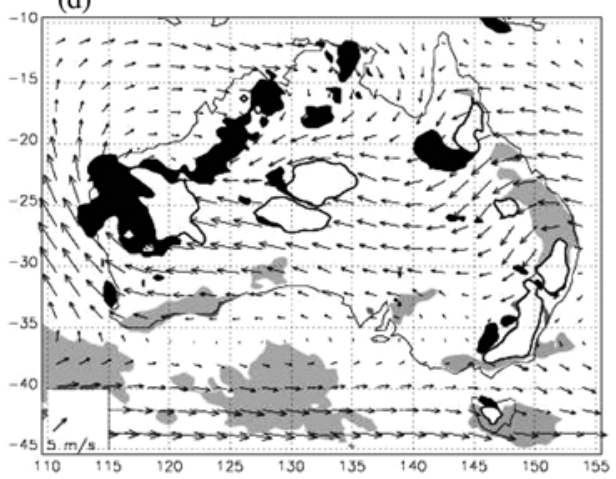

(f)

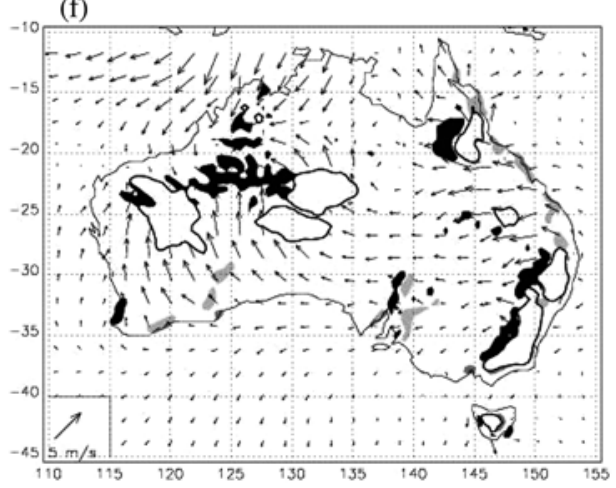

Figure 1. Mean-sea-level pressure at (a) 1600 AEST $(=\mathrm{UTC}+10 \mathrm{~h})$, and (b) 0400 AEST, with contour interval $1 \mathrm{hPa}$. Mean $925 \mathrm{hPa}$ total wind at (c) 1600 AEST and (d) 0400 AEST. Mean $925 \mathrm{hPa}$ ageostrophic wind at (e) 1600 AEST, and (f) 0400 AEST. Means are calculated using the DJF fields for 2000-2003. The dark black lines enclosing black areas show where the topography is higher than $950 \mathrm{hPa}$. Grey and black shaded areas indicate, respectively, regions: in (a) and (b) where the potential-temperature gradient exceeds $2 \times 10^{-5}$ and $4 \times 10^{-5} \mathrm{~K} \mathrm{~m}^{-1}$; in (c) and (d) where vorticity exceeds $1.5 \times 10^{-5} \mathrm{~s}^{-1}$ and is less than $-1.5 \times 10^{-5} \mathrm{~s}^{-1}$; in (e) and (f) where divergence exceeds $1 \times 10^{-5} \mathrm{~s}^{-1}$ and is less than $-1 \times 10^{-5} \mathrm{~s}^{-1}$. 
times are shown also in Figs. 1(c)-(f). Regions of convergence and vorticity are marked on each figure. The processes of averaging masks the individual fronts and troughs that traverse the continent, leaving only the background environment in which they develop. Figures 1(a) and (b) also show regions where the potential-temperature gradient exceeds $2 \times 10^{-5}$ and $4 \times 10^{-5} \mathrm{~K} \mathrm{~m}^{-1}$, respectively. This map reflects the frequency of strong sea-breeze circulations.

Strong horizontal potential-temperature gradients occur most frequently during the day along the south-western, southern and south-eastern coastlines. A pronounced heat low is located over the north-western part of the continent, and extends troughs towards the south-east and the south-west. This south-western extension is referred to as the west-coast trough. There are strong westerlies south of the continent, strong easterlies to the north-east, and westerlies to the north-west, the latter being associated with the cyclonic circulation around the heat low.

An anticyclonic circulation develops across the southern coastline and across the central part of the continent, and is reflected in the mean-sea-level pressure as a zonal extension of the Indian Ocean subtropical high across the south-western part of the continent. The southerlies along the west coast are part of the Indian Ocean subtropical anticyclone, and the associated deformation in the south-western part of the continent maintains the region of strong potential-temperature gradient throughout the night. A ridge lies along the central and northern parts of the east coast, and there is a weak trough in the south-eastern corner of the continent.

At night the coastal potential-temperature gradients weaken, the heat low fills by about $2 \mathrm{hPa}$, and the easterlies across the continent dramatically strengthen. The changes in the wind field are especially pronounced in the ageostrophic flow, which is southwesterly across much of the continent during the day, but turns anticyclonically during the night leading to easterlies across the eastern part of the continent and southerlies over the western part. During the day the convergence is confined mostly to the coastal margin, but at night strong convergence develops into the north-western heat low.

\section{THE NUMERICAL MODEL}

The model is a slightly modified version of the hydrostatic, primitive-equation model described by RS99. It uses finite differences and is formulated in $\sigma$-coordinates, where $\sigma=p / p_{\mathrm{s}}$, and $p$ and $p_{\mathrm{s}}$ are the pressure and surface pressure, respectively. There are 30 unequally spaced $\sigma$-levels in the vertical, with closer spacing in the lower atmosphere to better resolve the boundary layer. The lowest $\sigma$-levels are at approximately $9,44,105,219,317$ and $443 \mathrm{~m}$. The top of the domain is at a height close to $20 \mathrm{~km}$ and the horizontal resolution is $25 \mathrm{~km}$ compared with $100 \mathrm{~km}$ used by RS99. The horizontal coordinates $(x, y)$ refer to the zonal and meridional directions, respectively. For simplicity moisture is neglected.

A non-staggered Arakawa A-Grid is used in the horizontal and a staggered grid in the vertical with the horizontal velocity components $u$ and $v$, geopotential height $\phi$ and temperature $T$ defined at the $\sigma$-levels, and the vertical $\sigma$-velocity, $\dot{\sigma}=\mathrm{D} \sigma / \mathrm{D} t$, defined half way between the $\sigma$-levels. The scheme proposed by Miller and Pearce (1974) is used for time integration and a third-order upwind scheme is used for the horizontal advection. The horizontal diffusion scheme $K_{2} \nabla^{2} \varphi$ used by RS99 is replaced by $-K_{4} \nabla^{4} \varphi$, where $\varphi$ is either $u, v$ or $T$ and $K_{4}=5 \times 10^{13} \mathrm{~m}^{4} \mathrm{~s}^{-1}$. This scheme is preferred as it is less diffusive and more scale selective, damping mainly the smaller scales. 
Channel boundary conditions are applied at the northern and southern boundaries of the domain and periodic boundary conditions at the eastern and western boundaries. The use of periodic boundary conditions in the presence of zonal background flows limits the time for which the heat low remains unaffected by its downstream influence, a point that we return to in section $4(b)$. The vertical motion vanishes $(\dot{\sigma}=0)$ at the upper and lower boundaries. At the upper boundary $\partial u / \partial \sigma=\partial v / \partial \sigma=\partial T / \partial \sigma=0$. In the lowest atmospheric layer sensible-heat fluxes are calculated by similarity theory. A Mellor-Yamada 2.25 second-order closure parametrization scheme (Mellor and Yamada 1974, 1982) is used for the boundary layer above. The heat transport in the soil is calculated from a three-layer soil model with diffusive transports between the layers.

The flux of solar radiation at the top of the atmosphere is taken to be the same as that in RS99. The incoming short-wave flux at the surface is approximately $7.2 \mathrm{kWh} \mathrm{m}^{-2}$ per day and the albedo is set to 0.3 reflecting $30 \%$ back to space. The sea surface temperature is fixed at $25^{\circ} \mathrm{C}$. The domain is centred at $25.7^{\circ} \mathrm{S}\left(f\left(-25.7^{\circ}\right)=-6.33 \times 10^{-5} \mathrm{~s}^{-1}\right)$, which is slightly more appropriate to central Australia than the $20^{\circ} \mathrm{S}$ used by RS99.

The initial vertical profile of potential temperature assumes a uniform static stability in the troposphere and stratosphere with different Brunt-Väisälä frequencies $N^{2}=1.5 \times 10^{-4}$ and $3.5 \times 10^{-4} \mathrm{~s}^{-2}$, respectively. In contrast, RS99 used the mean Townsville sounding for November. The tropopause is set at a height of $16 \mathrm{~km}$, which corresponds with the mean height in the latitudes of interest, based on upper-air soundings from Alice Springs in central Australia. In the calculations with no background flow the initial surface pressure is set to $1016 \mathrm{hPa}$ uniformly in the whole domain, otherwise the pressure at the midpoint of the domain is set to $1016 \mathrm{hPa}$.

\section{NO BACKGROUND FLOW}

\section{(a) Initialization}

The configuration of these calculations is similar to that of RS99. Two different sized land masses are chosen to examine the effects of the size of the heated area: one has a side length of $600 \mathrm{~km}$ (referred to as the small land mass) and the other a side length of $1200 \mathrm{~km}$ (referred to as the large land mass). The sizes of the computational domains for numerical experiments with the small and large land mass are $2575 \mathrm{~km} \times$ $4000 \mathrm{~km}$ and $4050 \mathrm{~km} \times 6000 \mathrm{~km}$, respectively.

\section{(b) Flow evolution on a southern hemisphere $f$-plane}

Two model calculations are carried out on a southern hemisphere $f$-plane with no background flow: one for the small land mass (hereafter referred to as SN (Small land mass, No background flow)) and the other for the large land mass (LN). These are compared with the corresponding calculations from RS99, hereafter referred to as SR and LR.

RS99 found that, in the absence of a large-scale basic flow, a quasi-steady state was established after 11 days of model integration. In the presence of a background flow, the use of periodic boundary conditions in the horizontal limits the time for which the heat low remains unaffected by its downstream influence. For this reason all the analyses shown here are for days 3 and 4 of model integration, long enough for the heat low to spin up, but short enough for the upstream influence not to be significant. For example, with a $5 \mathrm{~m} \mathrm{~s}^{-1}$ zonal flow typical of calculations in later sections, an air parcel leaving the west coast would require about 4.5 days to reappear at the eastern edge of the plotting domain. 
The surface pressure distribution for LN at 1800 LST (local solar time) on day 3 and 0600 LST on day 4 of model integration shows a low over the centre of the land mass (Figs. 2(a) and (b)). The low deepens during the day, attaining its minimum surface pressure in the late afternoon, while the maximum pressure occurs in the morning. The shaded (dashed) regions in these panels show the corresponding relative vorticity below (above) $-(+) 5 \times 10^{-5} \mathrm{~s}^{-1}$, i.e. cyclonic (anticyclonic). The maximum cyclonic relative vorticity in LN is larger than in LR, but both maxima occur at approximately the same time and place. The larger values here can be attributed to the increased horizontal resolution of these calculations and the lower horizontal diffusion. At 1800 LST the vorticity values are maximum near the coast along the sea-breeze fronts (Fig. 2(a)), while at 0600 LST they are larger in magnitude and located in a cross-like pattern and along the sides of square inside this cross (Fig. 2(b)). These features are much less pronounced in LR. There is a dramatic decrease of cyclonic relative vorticity after sunrise, which is due to the mixing initiated by renewed surface heating, but the front remains evident in the vorticity field until midday. The lack of phase between the surface pressure and near-surface relative vorticity shows that the heat low is far from quasigeostrophic balance, even when the scale is large.

Figures 2(c) and (d) show the corresponding vertical cross-sections of potential temperature for $\mathrm{LN}$ through the centre of the land mass. A mixed layer forms over the land during the day as a result of surface heating, while at night a shallow surface-based stable layer develops due to the cooling of the land surface. In LN the depth of the mixed layer after three days is approximately $2.2 \mathrm{~km}$ and the surface-based stable layer does not exceed 200-300 $\mathrm{m}$ in depth. At the centre of the land mass, this layer is shallower and much weaker in LN and LR compared to SN and SR. The reason is that the sea breeze reaches the centre of the small land mass and supplements the nocturnal cooling there. The shaded regions in Figs. 2(c) and (d) show where the divergence exceeds $\pm 3 \times 10^{-5} \mathrm{~s}^{-1}$. The extreme values of horizontal convergence during the diurnal cycle in LN are almost twice as large as those in LR, again because of the finer horizontal resolution. The maximum convergence in LN occurs in the morning, just before vertical mixing destroys the surface inversion. Figure 2(c) shows a sea-breeze circulation at 1800 LST with a narrow region of low-level convergence just inland and a region of upper-level divergence above it. There is a region also of low-level divergence just offshore. By 0600 LST a very shallow region of strong convergence has formed along the edges of a square-like pattern over the land (not shown). This region marks the leading edge of the low-level jet, which does not quite reach the centre of the island. This convergence decays rapidly after sunrise with the demise of the jet and by 1000 LST has completely disappeared.

Figures 2(e) and (f) show the ageostrophic wind component at $100 \mathrm{~m}$ above the surface at 1800 LST on day 3 and 0600 LST on day 4, respectively. The maximum wind speed occurs in the early morning and coincides with a strong low-level jet (Fig. 2(f)). There is a dramatic demise of the low-level jet after sunrise caused by mixing induced by surface heating. Around sunset there is a decrease in the wind speed because cooling commences over the land in the late afternoon, but as the surface-based stable layer develops during the night the ageostrophic wind over the land increases. The shaded regions in these panels show where the potential-temperature gradient at $100 \mathrm{~m}$ above ground level exceeds $5 \times 10^{-5} \mathrm{~K} \mathrm{~m}^{-1}$. The maximum gradient occurs in the late afternoon and coincides with the sea-breeze front (Fig. 2(e)). Because of the higher resolution in LN, the maximum is much larger than in LR. The potential-temperature gradient in LN strengthens significantly in the early morning and until sunrise is twice as large as that in LR. The increase is a result of frontogenesis due to the strong 
(a)

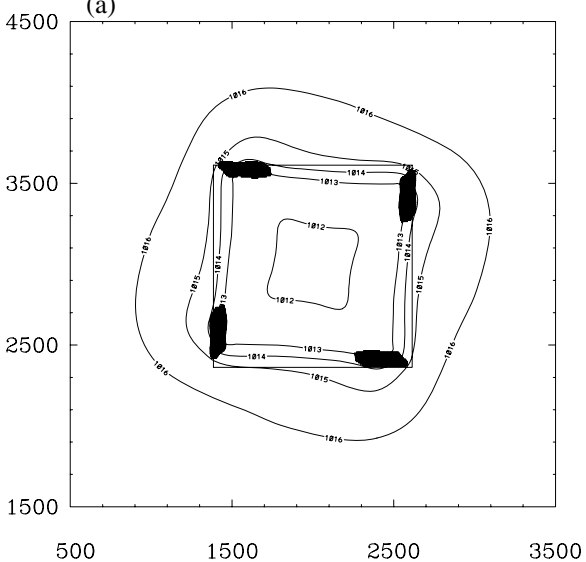

(c)

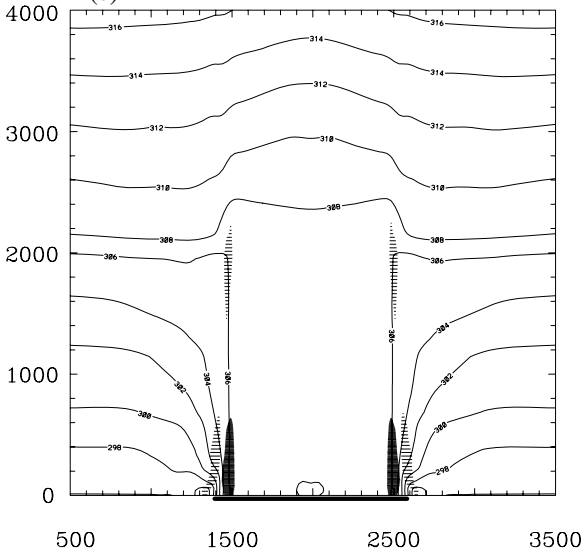

(e)

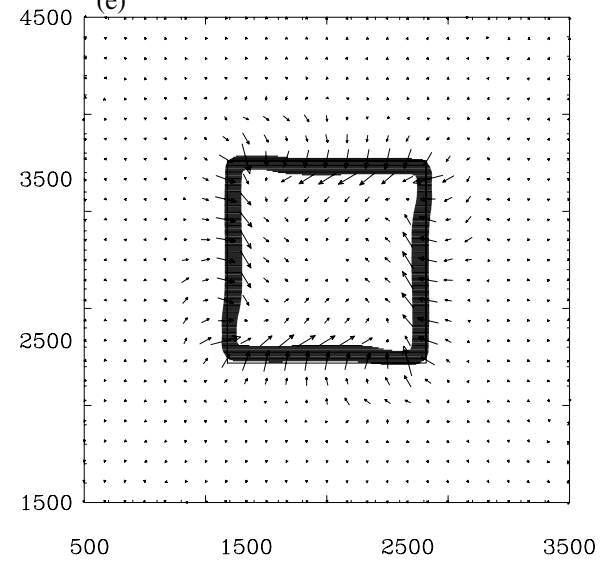

(b)

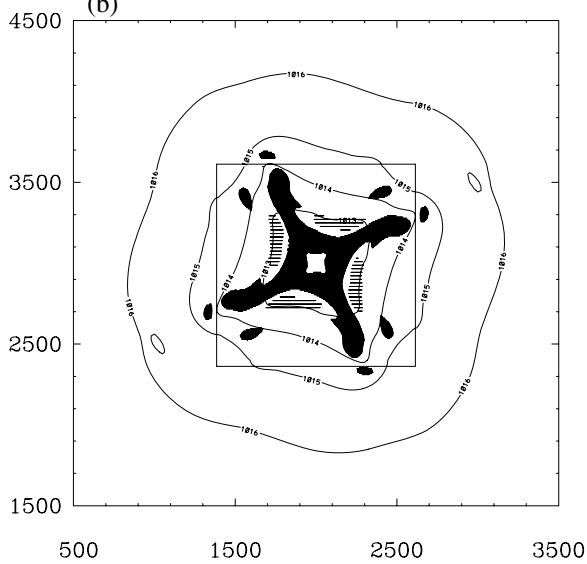

(d)

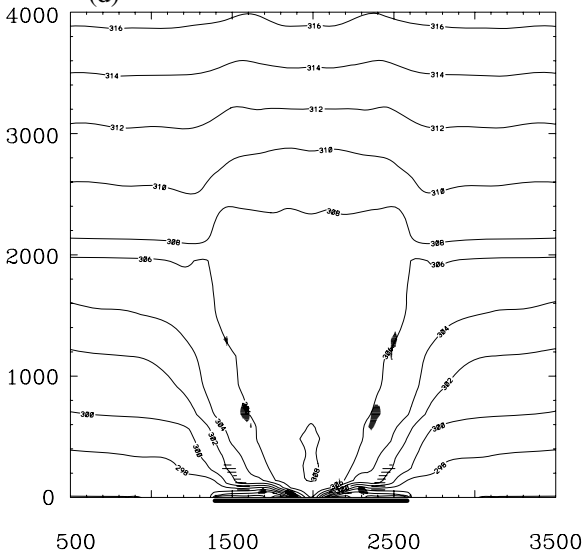

(f)

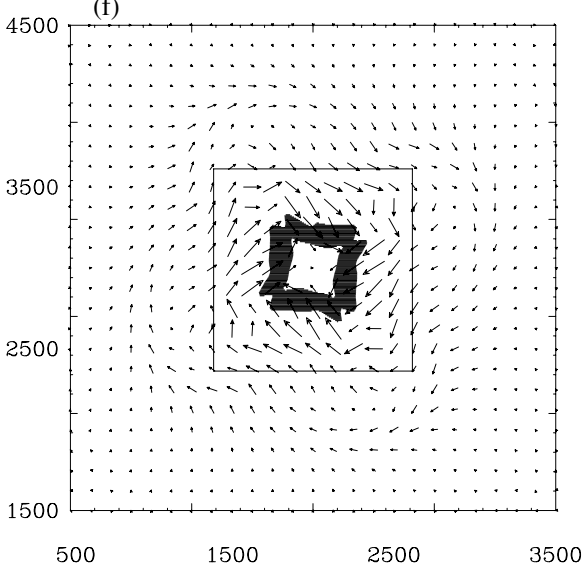

Figure 2. LN (Large land mass, No background flow, see text) on an $f$-plane. Left panels after $60 \mathrm{~h}$ (1800 LST, day 3), and right panels after $72 \mathrm{~h}$ (0600 LST, day 4). (a) and (b) Surface pressure (hPa) with areas dashed where vorticity at $100 \mathrm{~m}$ above ground level exceeds $5 \times 10^{-5} \mathrm{~s}^{-1}$, shaded where vorticity is less than $-5 \times 10^{-5} \mathrm{~s}^{-1}$; axes are marked in $\mathrm{km}$ and land mass marked by the square. (c) and (d) Vertical cross-section of potential temperature $(\mathrm{K})$ in the centre of the land mass with areas dashed where divergence exceeds $3 \times 10^{-5} \mathrm{~s}^{-1}$, shaded where divergence is less than $-3 \times 10^{-5} \mathrm{~s}^{-1}$; height is in metres and thick line represents the land mass. (e) and (f) Horizontal ageostrophic wind vectors with areas shaded where the potential-temperature gradient exceeds $5 \times 10^{-5} \mathrm{~K} \mathrm{~m}^{-1}$, both at $100 \mathrm{~m}$. 
convergence over the land. At 0600 LST on the 4th day the region of strong potentialtemperature gradient still forms along the edge of an approximate square. The slight clockwise turning of the fields shown in Figs. 2(b) and (f) is due to the anticlockwise (southern hemisphere) turning of the sea breeze as it moves inland. The inland front is rapidly destroyed by the renewed onset of mixing after sunrise and there are essentially no regions of strong potential-temperature gradient remaining over the continent at 1000 LST (figure not shown).

\section{(c) Small-land-mass calculations}

The fronts discussed above do not occur in the calculations for the small land mass, $\mathrm{SN}$ and SR. In these the sea breezes reach the centre of the land mass and spread cold air uniformly across it. Consequently strong horizontal temperature gradients do not develop at night.

\section{EASTERLY BACKGROUND FLOW}

We consider now the effects of a uniform easterly geostrophic background flow on the evolution of the heat low over the large land mass. We refer to this calculation as LB.

\section{(a) Initialization}

The initial conditions are the same as those in the previous section, with the exception that a uniform easterly geostrophic wind is added. The associated meridional surface pressure distribution is given by

$$
\frac{\partial p_{\mathrm{s}}}{\partial y}=-\frac{U_{\mathrm{g}} f p_{\mathrm{s}}}{R T_{\mathrm{s}}}
$$

from which it follows that

$$
p_{\mathrm{s}}=p_{0} \exp \left(\frac{-f U_{\mathrm{g}} y}{R T_{\mathrm{s}}}\right),
$$

where $p_{0}$ is a constant chosen to be $1016 \mathrm{hPa}$. Here $U_{\mathrm{g}}$ is the geostrophic wind speed, $R$ is the specific gas constant for dry air, $y$ is the distance in the meridional direction and $T_{\mathrm{s}}$ is the initial surface temperature. Following Noonan and Smith (1986) we take $U_{\mathrm{g}}=-5 \mathrm{~m} \mathrm{~s}^{-1}$, typical of the mean easterly airstream over the northern part of Australia (see also Fig. 1). The meridional boundary conditions on the temperature and the surface pressure are chosen to maintain the initial pressure and temperature gradients in the $y$-direction.

\section{(b) Flow evolution on a southern hemisphere f-plane}

The daily cycle of surface pressure over the land mass shows a maximum in the morning and a minimum just before sunset, but the amplitude of the cycle is only half as large $(0.3 \mathrm{hPa})$ as that without a background flow. Adding a mean easterly background flow results in the formation of a west-coast trough that by 1800 LST on day 3 nearly covers the whole land mass (Figs. 3(a) and (b)). The trough undergoes a diurnal cycle due to the heating and cooling of the land. It deepens during the day and weakens during the night as its meridional axis shifts slightly to the west. The shaded (dashed) regions in Figs. 3(a) and (b) show areas of relative vorticity at $100 \mathrm{~m}$ above ground level less 
(a)

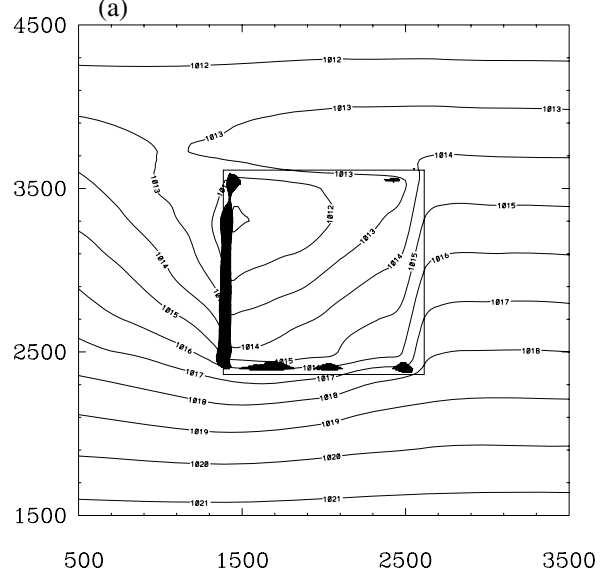

(c)

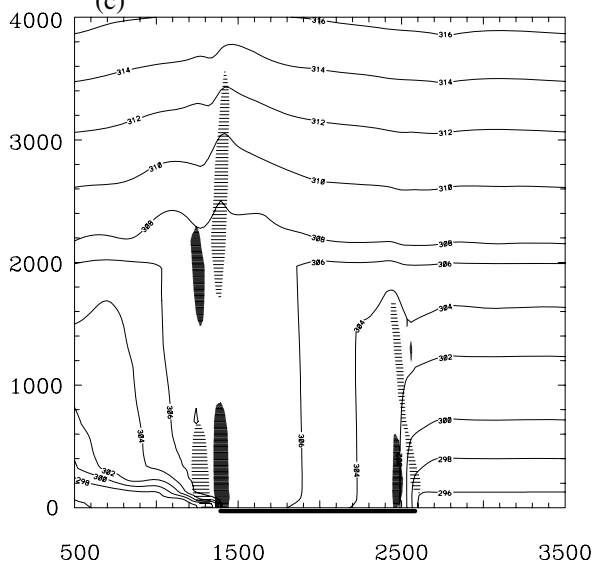

(e)

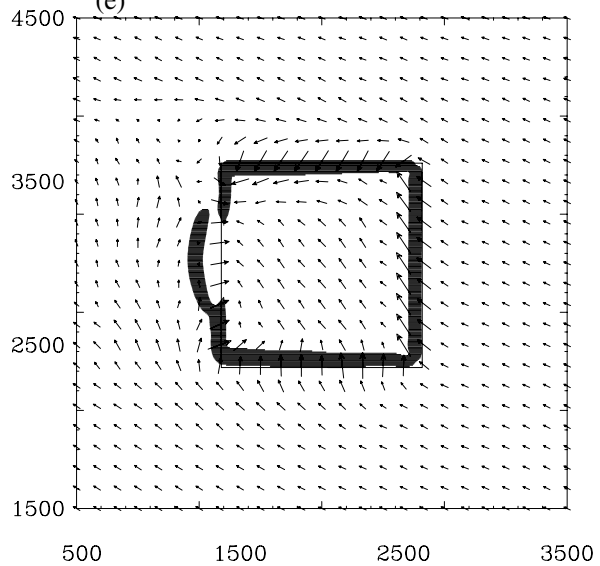

(b)

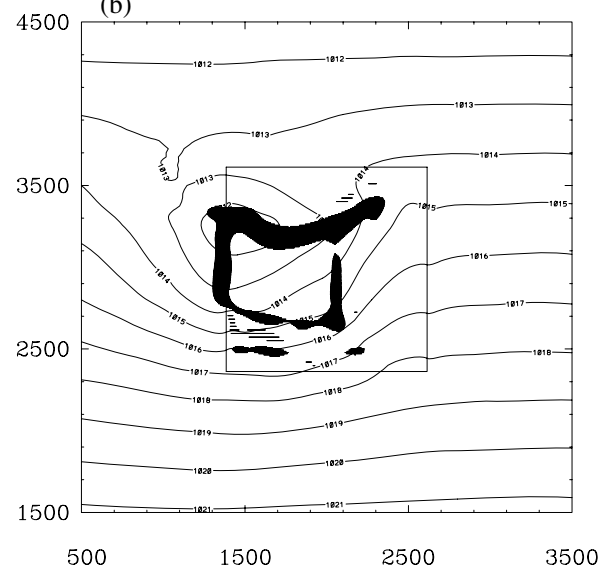

(d)

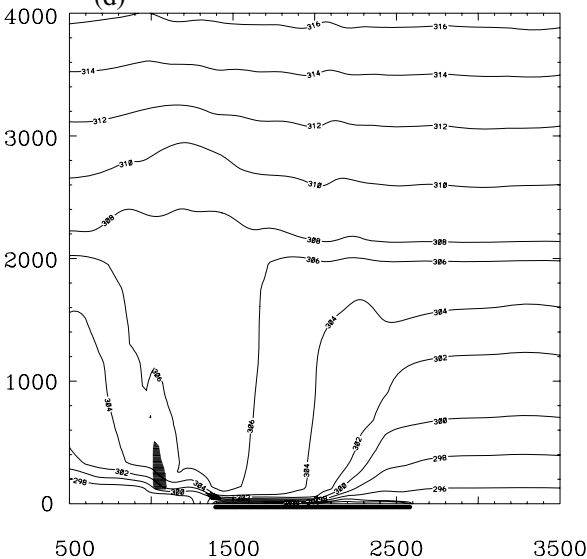

(f)

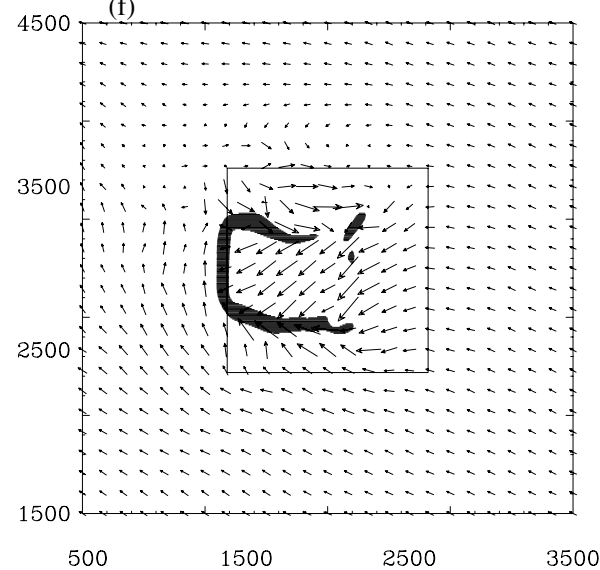

Figure 3. LB (Large land mass, uniform easterly background flow, see text) on an $f$-plane. Left panels after $60 \mathrm{~h}$ (1800 LST, day 3) and right panels after $72 \mathrm{~h}$ (0600 LST, day 4). (a) and (b) Surface pressure (hPa) with areas dashed where vorticity at $100 \mathrm{~m}$ above ground level exceeds $5 \times 10^{-5} \mathrm{~s}^{-1}$, shaded where vorticity is less than $-5 \times 10^{-5} \mathrm{~s}^{-1}$. Land mass is marked by the square. (c) and (d) Vertical cross-section of potential temperature in the centre of the land mass with areas dashed where divergence exceeds $3 \times 10^{-5} \mathrm{~s}^{-1}$, shaded where divergence is less than $-3 \times 10^{-5} \mathrm{~s}^{-1}$. (e) and (f) Horizontal ageostrophic wind vectors with areas shaded where the potentialtemperature gradient exceeds $5 \times 10^{-5} \mathrm{~K} \mathrm{~m}^{-1}$, both at $100 \mathrm{~m}$. Units are as in Fig. 2 . 
than (exceeding) $-(+) 5 \times 10^{-5} \mathrm{~s}^{-1}$. At 1800 LST on day 3 there is a strip of enhanced cyclonic relative vorticity marking the strong sea-breeze front along the west coast of the land and a broken strip marking the sea-breeze front just inland of the south coast. Elsewhere at this time, and indeed throughout the afternoon, the relative vorticity over the land is close to zero. At 0600 LST on day 4 the low has a more isolated appearance and within it are strips of enhanced cyclonic relative vorticity that are associated with a sharpening of the sea-breeze fronts from all four coastlines during the night (see also Fig. 3(e)).

The maximum surface temperatures are lower than those in LN because of the advection of cooler maritime air by the background flow over the land. Figures 3(c) and (d) show the corresponding vertical cross-sections of potential temperature through the centre of the land mass. In the evening the depth of the mixed layer over the land decreases towards the east due to the advection of cooler maritime air by the background flow. During the night a stable layer forms with a depth of 200-300 m and the warmer air is advected towards the west over the sea where it strengthens the maritime stable layer. Note that at 1800 LST the west-coast sea breeze has a well-defined front whereas the east-coast sea-breeze front is diffuse. The shaded regions in these panels show regions of significant horizontal divergence and convergence. During the day the divergence is confined to the coasts with a maximum near the west coast: indeed the west-coast seabreeze circulation is much stronger and deeper than that of the east-coast sea breeze (see Fig. 3(c)). At 0600 LST (Fig. 3(d)) there is strong low-level convergence into the trough just off shore of the west coast.

Figures 3(e) and (f), show regions of potential-temperature gradient exceeding $5 \times 10^{-5} \mathrm{~K} \mathrm{~m}^{-1}$ at a height of $100 \mathrm{~m}$ together with the ageostrophic wind vectors at this level at 1800 LST on day 3 and 0600 LST on day 4. During the day the strongest ageostrophic winds are associated with the sea breeze (Fig. 3(e)), which at 1800 LST is marked by a region of strong potential-temperature gradient along and just inland from the coast. Note that the sea-breeze front along the central west coast is pushed a little offshore by the background flow. By 0600 LST the sea-breeze fronts from the north and south coasts have moved a considerable distance inland, while that from the west coast has contracted to the coast and that from the east coast has become more diffuse, even though it retains a signature in the relative vorticity (Fig. 3(b)). Moreover, there is strong ageostrophic convergence into these frontal regions (Fig. 3(f)).

The trough/heat low in this calculation shows similar features to those observed in a heat low over Australia by Preissler et al. (2002). These features include the development overnight of narrow strips of strong low-level convergence, locally large potential-temperature gradient, and enhanced cyclonic vorticity along axes within the low. The observations show also the formation of a shallow front in the early morning as a result of the acceleration and inertial turning of the low-level jet. This front decayed rapidly after sunrise also.

\section{(c) Small-land-mass calculations}

The experiment with the small land mass does not produce such strong fronts. The main feature is the collision of the two sea breezes. Once the mixing is suppressed and a surface inversion develops, the sea breeze on the east coast accelerates dramatically and collides with the west-coast sea breeze approximately $100 \mathrm{~km}$ inland from the west coast. This phenomena has been studied in detail in idealized two-dimensional calculations by Noonan and Smith (1986) and Goler and Reeder (2004). 


\section{HORIZONTALLY SHEARED BACKGROUND FLOW}

\section{(a) Initialization}

The initial fields are the same as those in the section 4, but with appropriate changes made to the surface pressure and the geostrophically balanced wind field. The expressions for the surface pressure and the geostrophic wind are

$$
p_{\mathrm{s}}=p_{0}(\cosh (y / D))^{\left(-f U_{\mathrm{g} 0} D\right) /\left(R T_{\mathrm{s}}\right)}
$$

and

$$
U_{\mathrm{g}}=U_{\mathrm{g} 0} \tanh (y / D),
$$

where $D=1.33 \times 10^{5} \mathrm{~m}$ measures the width of the shear region, $U_{\mathrm{g} 0}$ is the geostrophic wind at large meridional distances and $p_{0}=1016 \mathrm{hPa}$. These profiles are defined separately for the northern and southern halves of the domain, which allows us to investigate asymmetric shear flows with different values for $U_{\mathrm{g} 0}$ in these two subdomains.

Three sheared flow fields are investigated. The first, LD1, has a symmetric wind field about $y=0$ with a $5 \mathrm{~m} \mathrm{~s}^{-1}$ easterly in the northern half and a $5 \mathrm{~m} \mathrm{~s}^{-1}$ westerly in the southern half. The second, LD2, has an asymmetric field with a $5 \mathrm{~m} \mathrm{~s}^{-1}$ easterly in the northern half and a $10 \mathrm{~m} \mathrm{~s}^{-1}$ westerly in the southern half, and the third, LD3, is similar to LD2, but with the wind strengths reversed. The aim is to use idealized representations of the deformation field that occurs when a trough approaches the Australian continent from the south-west. In such situations the subtropical ridge lies over the northern part of Australia and there is easterly flow to its north and westerly flow to its south. In principle the foregoing shear flows might be barotropically unstable. We checked that the magnitude of the shear is not large enough to initiate instabilities on the time and space scales relevant to the calculations here by integrating the model with the shear flow alone without diabatic forcing. An 11-day integration showed no growing disturbances.

As in section 5, the meridional boundary conditions for the temperature and the surface pressure fields are designed so that the initial pressure and temperature gradients are maintained.

\section{(b) Flow evolution on a southern hemisphere f-plane}

Figure 4 shows similar fields to those in Figs. 2 and 3 for the calculation LD2, again at 1800 LST on day 3 and at 0600 LST on day 4 of model integration. At 1800 LST the surface pressure field in LD2 shows a well-pronounced trough in the westerlies lying diagonally from north-west to south-east across the whole land mass. In contrast, the calculation LD3 produces a trough in the easterlies (not shown), while the calculation LD1 produces an oval-shaped low pressure system symmetric along the north-west to south-east diagonal across the land mass. As in the experiment with the uniform background flow, the trough broadens over most of the land during the day (Fig. 4(a)) due to heating, while it sharpens during the night (Fig. 4(b)). Figures 4(a) and (b) also show regions of relative vorticity exceeding (less than) $+(-) 5 \times 10^{-5} \mathrm{~s}^{-1}$. In the late afternoon, the maximum vorticity is confined to narrow strips just inland from the northsouth coastlines where the broadscale flow is offshore (Fig. 4(a)). Around sunrise the maximum cyclonic vorticity is located in a diagonal strip stretching north-west to southeast across the land with a second strip oriented west-south-west to east-north-east over the southern half of the land. As in previous large-land-mass calculations, these strips of enhanced cyclonic vorticity are associated with shallow fronts that emerge overnight from the inland-penetrating sea-breeze fronts and are confined to levels below $1 \mathrm{~km}$. 
(a)

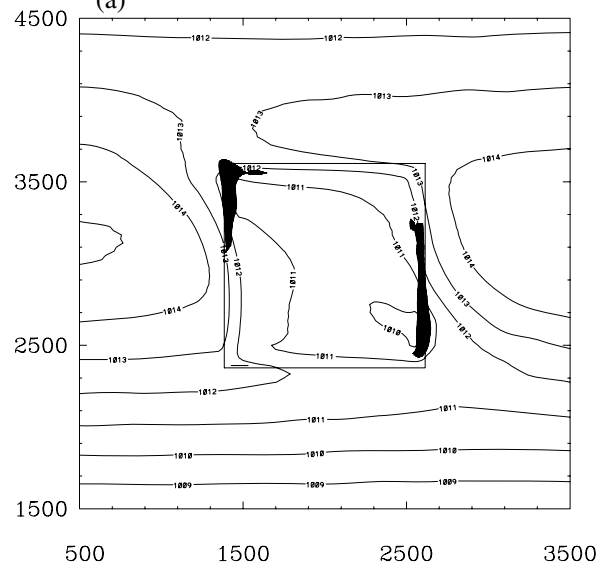

(c)

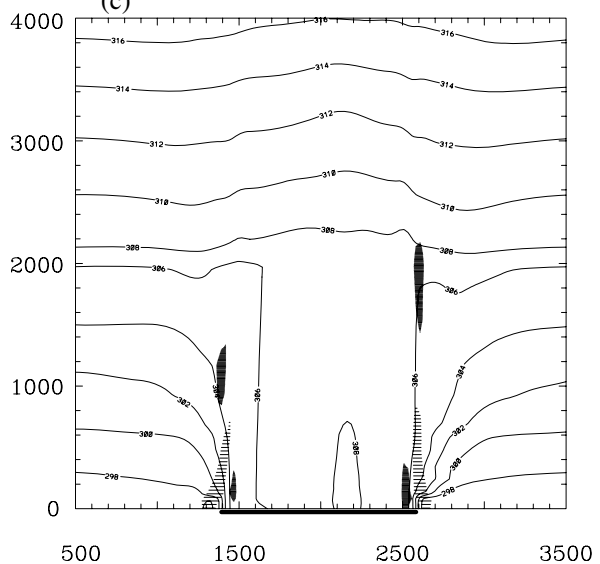

(e)

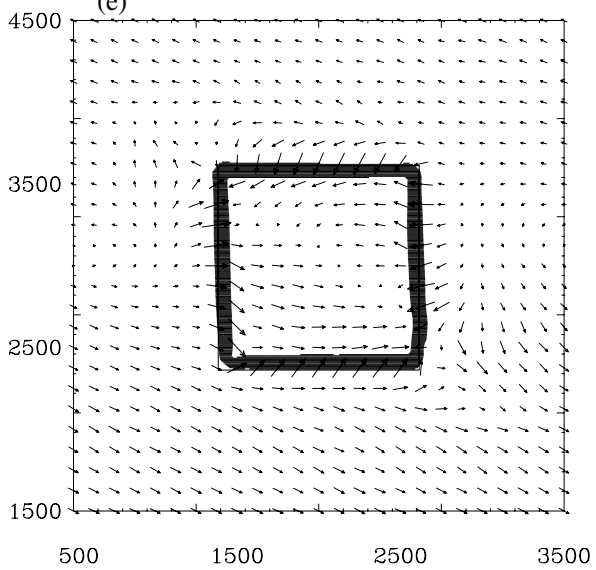

(b)

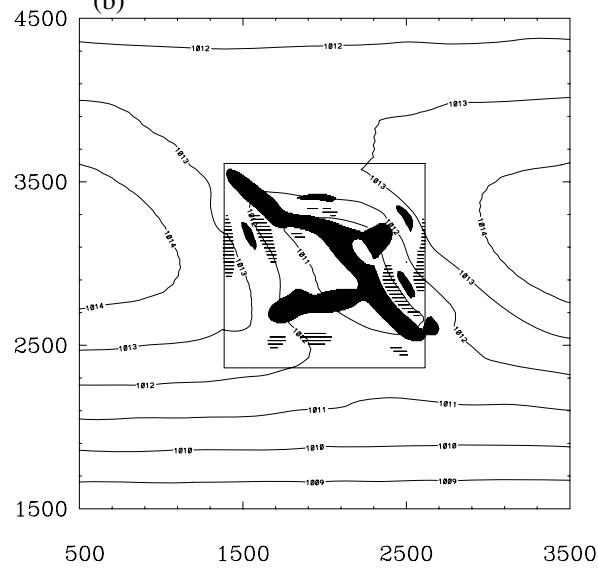

(d)

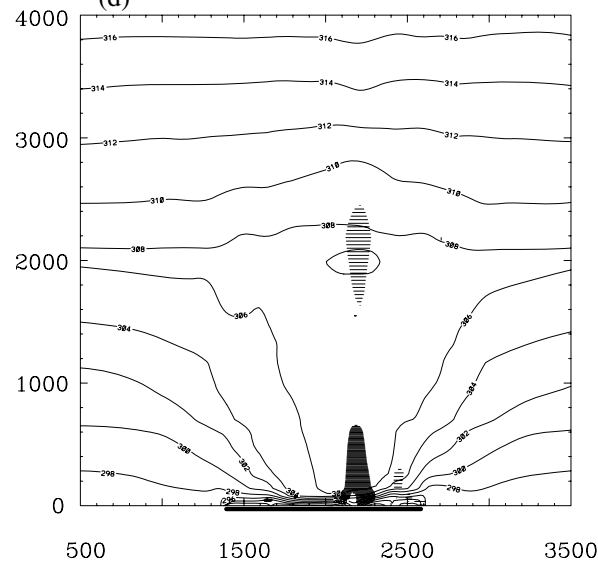

(f)

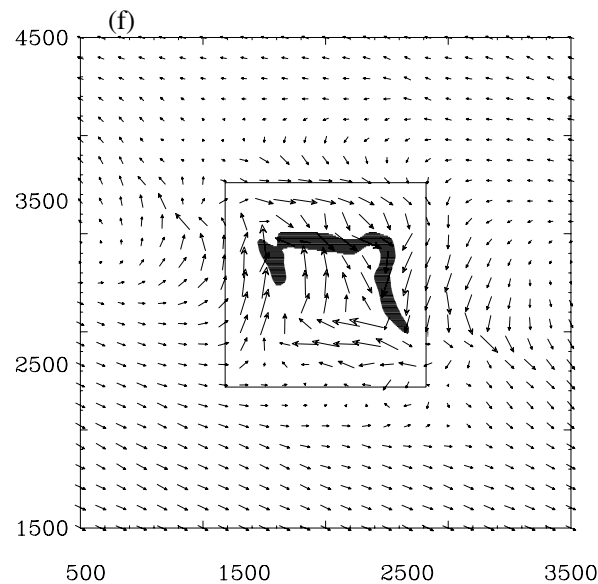

Figure 4. LD2 after $60 \mathrm{~h}$ (1800 LST, day 3) (left panels) and $72 \mathrm{~h}$ of time integration (0600 LST, day 4) (right panels). (a) and (b) Surface pressure $(\mathrm{hPa})$ with areas dashed where vorticity at $100 \mathrm{~m}$ above ground level exceeds $5 \times 10^{-5} \mathrm{~s}^{-1}$, shaded where vorticity is less than $-5 \times 10^{-5} \mathrm{~s}^{-1}$. Land mass is marked by the square. (c) and (d) Vertical cross-section of potential temperature $(K)$ in the centre of the land mass with areas dashed where divergence exceeds $3 \times 10^{-5} \mathrm{~s}^{-1}$, shaded where divergence is less than $-3 \times 10^{-5} \mathrm{~s}^{-1}$. (e) and (f) Horizontal ageostrophic wind vectors with areas shaded where the potential-temperature gradient exceeds $5 \times 10^{-5} \mathrm{~K} \mathrm{~m}^{-1}$, both at $100 \mathrm{~m}$. Units as in Fig. 2 . 
In the symmetric deformation case the vorticity pattern is oval-shaped and looks somewhat smoother than in LD2 and LD3. The fronts decay after sunrise due to the turbulent mixing initiated by surface heating, but their remnants can still be detected until about midday. They reform the following night and peak in the morning before the inversion is again destroyed.

Changes in the vertical structure of potential temperature over the centre of the land mass between 1800 LST and 0600 LST (Figs. 4(c) and (d)) are similar to those in LN (Figs. 2(c) and (d)), but with an asymmetry because of the stronger westerly wind in the southern half of the domain. The surface inversion is quite shallow during the first two nights, but becomes stronger and deeper during the third night because of the higher wind speeds. These strong winds enhance the vertical fluxes of cooler surface air upwards at night, providing conditions suitable for the formation of a nocturnal lowlevel jet.

The afternoon peak in near surface convergence along the coast in Fig. 4(c) is associated with the sea breeze. After sunset, convergence occurs over the land due to the inland penetration of the sea breeze. As shown in Fig. 6(a), where the horizontal divergence exceeding (less than) $+(-) 3 \times 10^{-5} \mathrm{~s}^{-1}$ at $100 \mathrm{~m}$ above ground level is shaded (dashed), the region of convergence becomes deformed by the background shear to a region of enhanced convergence.

The vertical velocity distribution at $1500 \mathrm{~m}$ above ground level shows that at 0600 LST on day 4 there is ascent along the warm side of the front (Fig. 6(b)). Figure 4(d) shows that the region of enhanced convergence over the land does not exceed a height of $800 \mathrm{~m}$. After 1000 LST there are no regions of enhanced convergence over the land since turbulent mixing due to surface heating rapidly destroys the front.

The region where the potential-temperature gradient at $100 \mathrm{~m}$ above ground level exceeds $5 \times 10^{-5} \mathrm{~K} \mathrm{~m}^{-1}$ is shaded in Figs. 4(e) and (f). In the late afternoon the pattern is similar to the one in the LN calculation (cf. Fig. 4(e) with Fig. 2(e)) because of the large land-sea temperature contrast at this time. However, the spatial distribution of the potential-temperature gradient during the night is very different and is strongly affected by the deformation field. After sunset the sea breezes begin to penetrate inland and undergo an anticlockwise inertial turning. Figure 5 shows a time sequence of the potential-temperature distribution and horizontal wind vectors at $100 \mathrm{~m}$ above ground level for the LD2 calculation. The plots are at six-hourly intervals from 1800 LST on day 3 until midday on day 4 . The flow field is frontogenetic overnight and concentrates the isentropes to form a shallow front (Fig. 5(c)). The front is clearly marked also by the strip of enhanced relative vorticity shown in Fig. 4(b). After sunrise, convective mixing destroys this front so that by midday there is no trace of it over the land (Fig. 5(d)). In the symmetric calculation LD1, two fronts form symmetrically about the north-west to south-east diagonal across the island.

The observations by Hanstrum et al. (1990b) indicate that moving prefrontal troughs over Australia are associated with westerly troughs so that the calculation LD2 is more relevant to central Australian fronts. The calculation LD3 was carried out for completeness. As expected, the flow develops the structure of an easterly trough (not shown) with features that are the mirror image of those in LD2.

\section{(c) Small-land-mass calculation}

The deformation calculations were performed also for the small-land-mass case, but as in previous cases fronts do not form overnight because the sea breezes collide over the land. 
(a)

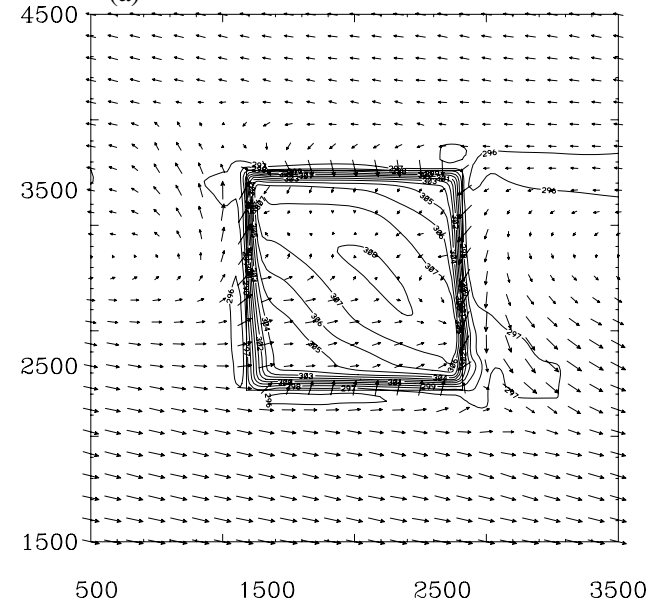

(c)

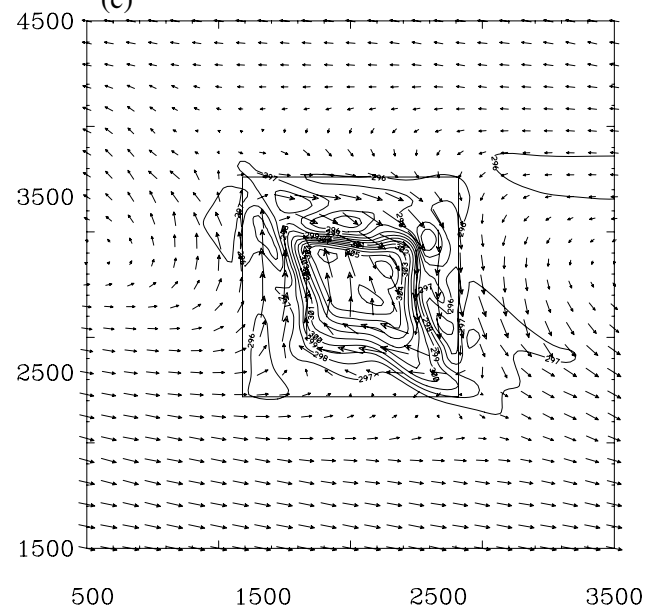

(b)

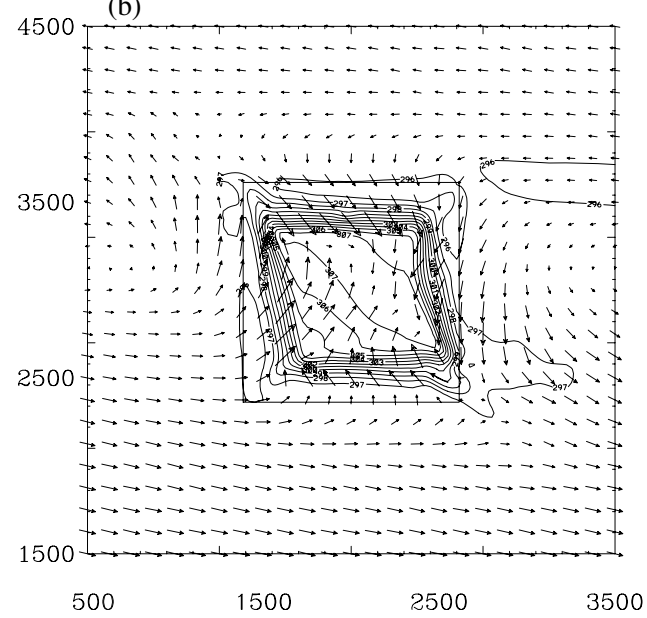

(d)

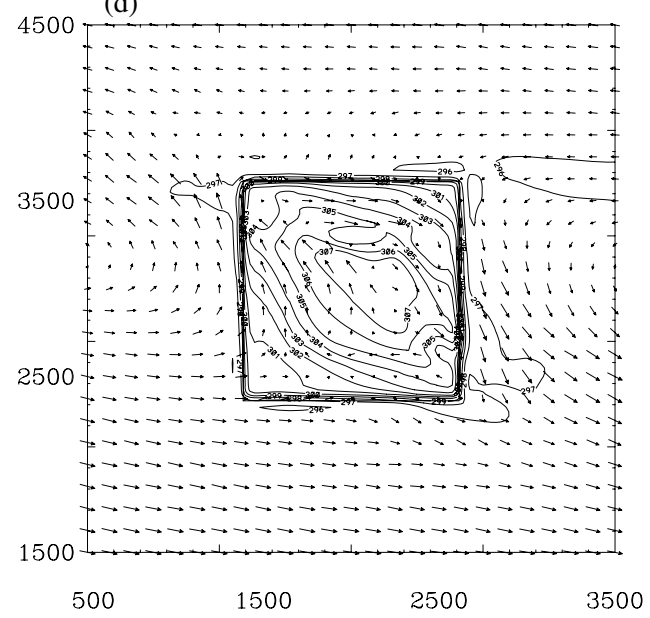

Figure 5. Potential temperature (K) and wind vectors at $100 \mathrm{~m}$ above ground level at (a) 1800 LST on day 3 , and (b) 0000 LST, (c) 0600 LST and (d) 2400 LST on day 4 of model integration for LD2 (see text); axes are marked in $\mathrm{km}$.

\section{(d) Midlatitude calculation}

The experiment for the large land mass was performed also on a midlatitude $f$-plane centred at $45^{\circ} \mathrm{S}$. There was no adjustment of the solar radiation scheme to midlatitudes and hence the higher-latitude effect is 'felt' only in the increased Coriolis force. The essential differences are highlighted by a comparison of two sets of fields for the midlatitude calculation with the corresponding fields for the subtropical calculation LD2. Figure 7(a) shows the surface pressure field at 0600 LST on day 4 with areas of enhanced relative vorticity at $100 \mathrm{~m}$ above the surface superimposed, and Fig. 7(b) shows the ageostrophic wind vectors at $100 \mathrm{~m}$ above the surface with areas of enhanced potential-temperature gradient at that level superimposed at the same time. These should be compared with Figs. 4(b) and (f). The frontal structure in the morning has a similar strength in both calculations, but is located closer to the coast in the midlatitude calculation because the sea breeze is unable to penetrate as far inland on account of the increased inertial constraint. 
(a)

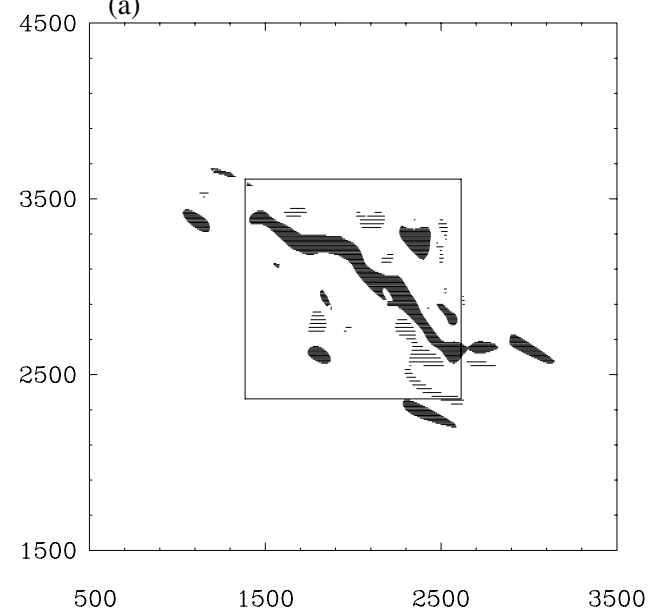

(b)

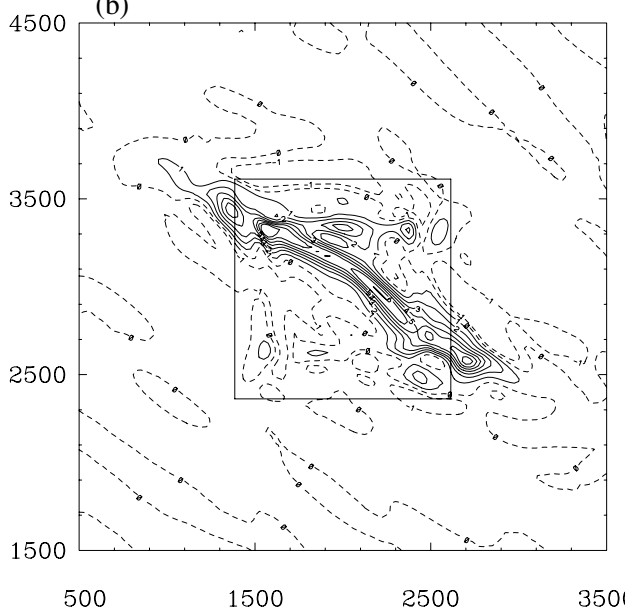

Figure 6. (a) Shaded (dashed) when divergence is less than (exceeds) $-(+) 3 \times 10^{-5} \mathrm{~s}^{-1}$ convergence, (divergence) for LD2 at $100 \mathrm{~m}$ above ground level, and (b) vertical velocity $\left(\mathrm{cm} \mathrm{s}^{-1}\right) 1500 \mathrm{~m}$ above ground level, both at $0600 \mathrm{LST}$ on day 4 . Axes are marked in $\mathrm{km}$.

(a)

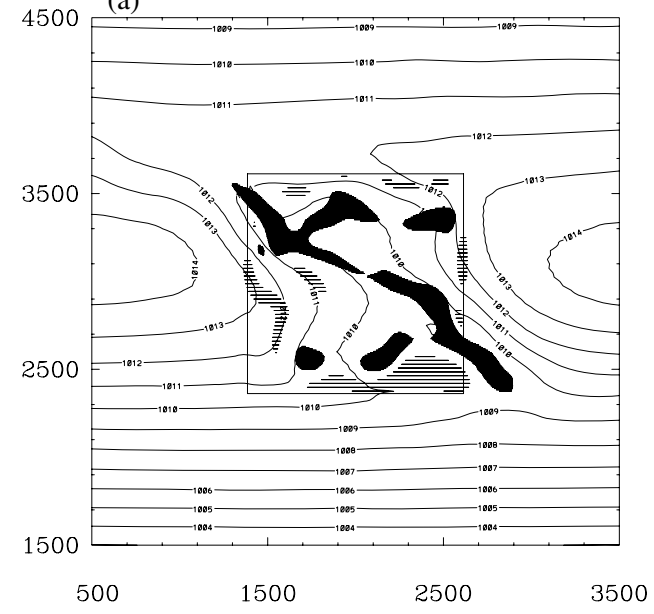

(b)

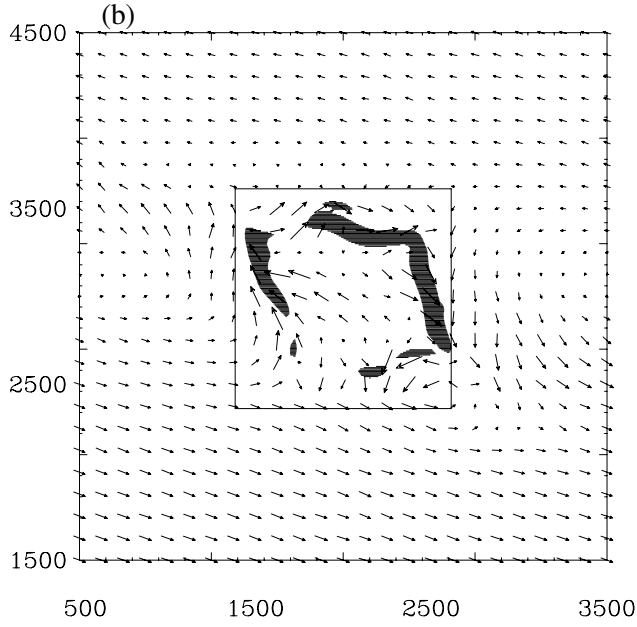

Figure 7. LD2 in the midlatitudes after $72 \mathrm{~h}$ of time integration (0600 LST, day 4) showing (a) surface pressure $(\mathrm{hPa})$ with areas where vorticity at $100 \mathrm{~m}$ above ground level exceeds $5 \times 10^{-5} \mathrm{~s}^{-1}$ (dashed) or where vorticity is cyclonic and less than $-5 \times 10^{-5} \mathrm{~s}^{-1}$ (shaded), (b) horizontal ageostrophic wind vectors with areas shaded where the potential-temperature gradient exceeds $5 \times 10^{-5} \mathrm{~K} \mathrm{~m}^{-1}$, both at $100 \mathrm{~m}$ above ground level. Axes marked in $\mathrm{km}$.

\section{(e) Continental-size-land-mass calculations}

The calculation LD2 was repeated for a continental-scale land mass with a length of $5000 \mathrm{~km}$ in the zonal direction and $3500 \mathrm{~km}$ in the meridional direction, typical of the size of the Australian continent. The domain size for this experiment is $16000 \mathrm{~km}$ $\times 10000 \mathrm{~km}$ and the calculation is again for an $f$-plane centred at $25.7^{\circ} \mathrm{S}$. Because of the longer spin-up time of the heat low in this case, the analyses are presented for days 9 and 10 . 
(a)

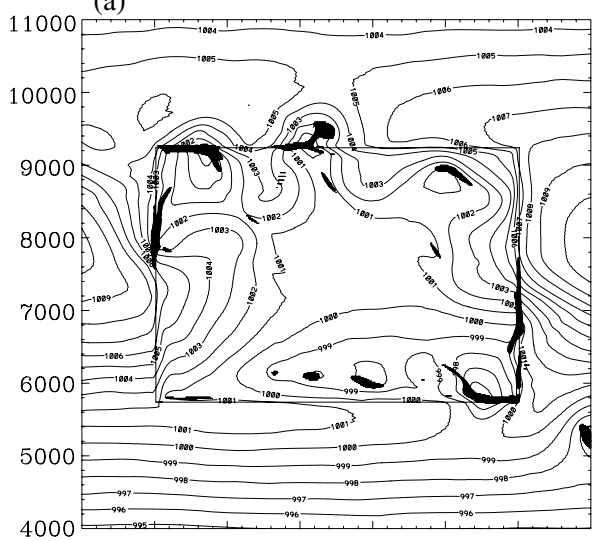

$15002500 \quad 3500 \quad 4500 \quad 5500 \quad 6500 \quad 7500 \quad 8500$

(c)

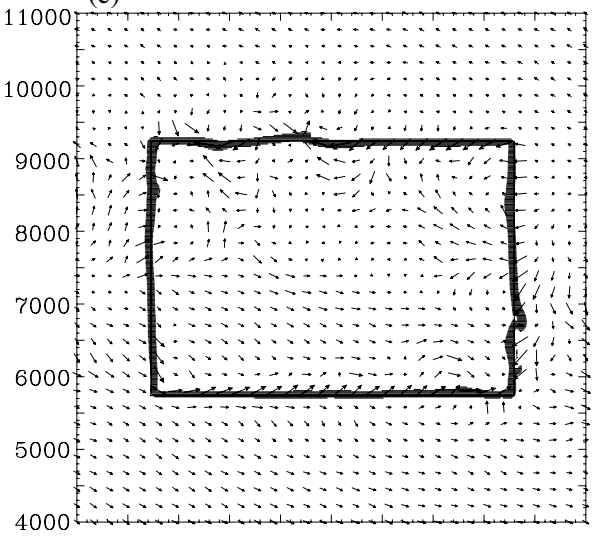

$15002500 \quad 3500 \quad 4500 \quad 5500 \quad 6500 \quad 7500 \quad 8500$ (b)

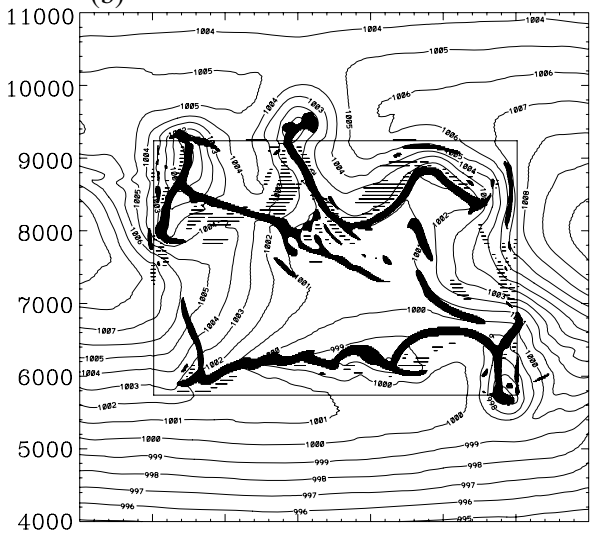

$15002500 \quad 3500 \quad 4500 \quad 5500 \quad 6500 \quad 7500 \quad 8500$

(d)

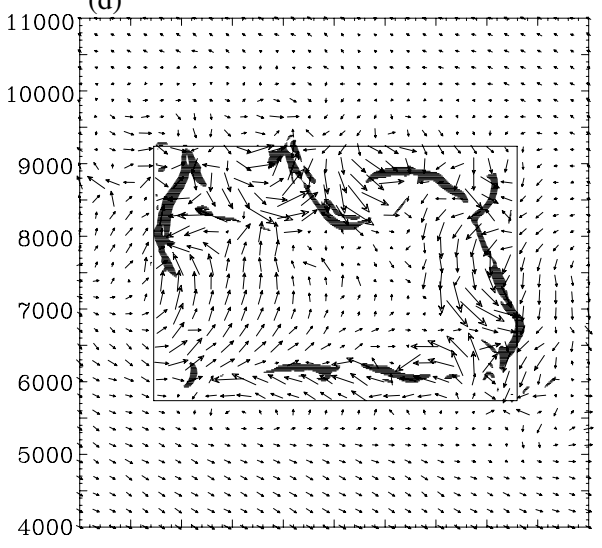

$15002500 \quad 3500 \quad 4500 \quad 5500 \quad 6500 \quad 7500 \quad 8500$

Figure 8. LD2 with a continental-size land mass at 1800 LST on the 9th day (left panels) and 0600 LST on the 10th day (right panels) showing (a) and (b) surface pressure (hPa) with areas dashed where the relative vorticity at $100 \mathrm{~m}$ above ground level exceeds $5 \times 10^{-5} \mathrm{~s}^{-1}$, and shaded where vorticity is less than $-5 \times 10^{-5} \mathrm{~s}^{-1}$; (c) and (d) horizontal ageostrophic wind vectors, with areas shaded where the potential-temperature gradient exceeds $5 \times 10^{-5} \mathrm{~K} \mathrm{~m}^{-1}$, both at $100 \mathrm{~m}$ above ground level. Axes marked in $\mathrm{km}$.

The surface pressure at 1800 LST on day 9 for this calculation is shown in Fig. 8(a). Again there is low pressure over the land, but in this case three troughs have formed in the north, one in the north-western corner, another one in the north-eastern corner and one in the middle of the northern part of the land mass. There is a trough also inland from the south coast. The same troughs are present at 0600 LST (Fig. 8(b)), but the trough in the north-west is sharper than on the previous evening.

Figures 8(a) and (b) show also shaded (dashed) regions of relative vorticity less than (exceeding) $-(+) 5 \times 10^{-5} \mathrm{~s}^{-1}$ in magnitude. At 1800 LST there are a few regions of enhanced cyclonic vorticity (Fig. 8(a)), mainly near the coast and connected to the troughs, whereas at 0600 LST the regions have become extensive over the land reaching some $1000 \mathrm{~km}$ inland (Fig. 8(b)). While the main strips of enhanced vorticity at $0600 \mathrm{LST}$ in the northern part of the land mass are connected to the troughs, there are regions also inland from the south coast, with increasing inland penetration towards the east. 
Figures 8(c) and (d) show the ageostrophic wind vectors at $100 \mathrm{~m}$ above ground level at 1800 LST on day 9 and 0600 LST on day 10. A large diurnal change is evident in these two panels with strong convergence into the three troughs in the northern half of the land mass at 0600 LST. Figures 8 (c) and (d) also show regions of potentialtemperature gradient in excess of $5 \times 10^{-5} \mathrm{~K} \mathrm{~m}^{-1}$. Whereas the shaded regions at 1800 LST (Fig. 8(c)) are solely connected to the sea-breeze front, again there are fronts evident some $1000 \mathrm{~km}$ inland at $0600 \mathrm{LST}$ (Fig. 8(d)). The fronts in the northern half of the land mass are connected to the three troughs generated by the strong convergence analysed in the ageostrophic wind vectors. This calculation shows that a continental-size land mass produces different results to the large-land-mass calculations discussed above. The fields analysed here show great similarity to the results presented by Preissler $\mathrm{et}$ al. (2002), who analysed the evolution of a heat low over the Australian continent in similar synoptic conditions to the one discussed in this section.

\section{(f) Flow evolution on a $\beta$-plane}

The foregoing calculations with and without a basic flow were repeated on a southern hemisphere $\beta$-plane, but the flow patterns are very similar to those that develop in the $f$-plane calculations. The main difference is an asymmetry in the inland penetration of the sea breeze, which decreases with increasing latitude because of the larger inertial constraint.

\section{CONCLUSIONS}

The flow induced by heated land masses of different sizes surrounded by sea has been investigated for three different large-scale environments (quiescent basic state, uniform background flow, and a zonal shear-flow). In all cases, nocturnal frontogenesis occurs along the sea-breeze fronts over the larger land masses, whereas for small land masses the sea breezes collide relatively early and spread cool air over the land area. These nocturnal fronts are more prominent in the present calculations than in previous ones on account of the increased horizontal resolution and lower horizontal diffusion. Inclusion of a variable Coriolis parameter has only a minor effect in all the calculations, the primary influence being the meridional asymmetry it brings about in the inland penetration of the sea breeze.

The calculations isolate some of the dynamical processes that appear to be responsible for important features of the mean low-level flow in the Australian region. For example, the introduction of an easterly geostrophic background flow results in a west-coast trough as found in earlier model studies. The solutions highlight the strong low-level convergence into the trough during the night that leads to frontogenesis, an aspect not considered by previous authors. The relative vorticity undergoes a strong diurnal variation also, being strongest and cyclonic in the trough axis at night. The model fields show many similarities to a recent observational analysis.

We have also investigated the deformation of a heat trough in a horizontal shearflow, a mechanism that is thought to play an important role in the formation of fronts over central Australia. The model develops shallow cold fronts during the night in regions of strong convergence over the land. These fronts decay rapidly with the onset of turbulent mixing after sunrise. The mechanisms associated with the nocturnal strengthening and daytime weakening of the cold fronts provide an explanation for the observations of frontal behaviour over central Australia.

Perhaps the main difference between the fronts observed over central Australia and those modelled here is the origin of the initial thermal gradient that contracts at night. 
In the model, the initial temperature contrast is provided by the cool air advected inland by the sea breezes along all coastlines, whereas in reality the initial temperature gradient over central Australia arises because of the equatorward advection of cool air following the passage of a midlatitude cold front.

\section{ACKNOWLEDGEMENTS}

We thank Sarah Arnup for providing Fig. 1. Most of the work presented here was done during a year-long visit to Monash University by Thomas Spengler. This was mainly financed through a Deutscher Akademischer Austausch Dienst (DAAD, German Academic Exchange Service) scholarship, for which Thomas Spengler is deeply grateful. In addition the authors wish to thank the anonymous reviewers for their comments.

Ackermann, S. A. and Cox, S. K.

Adams, $\mathrm{M}$.

Alonso, S., Portela, A. and Ramis, C.

Bitan, A. and Sa'aroni, $\mathrm{H}$.

Blake, D. W., Krishnamurti, T. N., Low-Nam, S. V. and Fein, J. S.

Deslandes, R., Reeder, M. J. and Mills, G.

Douglas, M. W. and Li, S.

Fandry, C. B. and Leslie, L. M.

Gaertner, M. A., Fernández, C. and Castro, $\mathrm{M}$.

Goler, R. A. and Reeder, M. J.

Hanstrum, B. N., Wilson, K. J. and Barrell, S. L.

Hoinka, K. P. and Castro, M.

Joshi, P. C. and Desai, P. S.

Junning, L., Zhengan, Q. and Fumin, $\mathrm{S}$.

Kepert, J. D. and Smith, R. K.

Leslie, L. M. and Skinner, T. C. L.
1982

1993

1994

1992

1983

1999

1996

1984

1993

2004

1990a

1990b

2003

1985

1986

1994

\section{REFERENCES}

The Saudi Arabian heat low: Aerosol distribution and thermodynamic structure. J. Geophys. Res., 87, 8991-9002

A linear study of the effects of heating and orography on easterly airstreams with particular reference to northern Australia. Aust. Meteorol. Mag., 42, 69-80

First considerations on the structure and development of the Iberian thermal low-pressure system. Ann. Geophys., 12, $457-468$

The horizontal and vertical extension of the Persian Gulf pressure trough. Int. J. Climatol., 12, 733-747

Heat low over the Saudi Arabian desert during May 1979 (Summer MONEX). Mon. Weather Rev., 111, 1759-1775

Synoptic analyses of a subtropical cold front observed during the 1991 Central Australian Fronts Experiment. Aust. Meteorol. Mag., 48, 87-110

Diurnal variation of the lower-troposphere flow over the Arizona low desert from SWAMP-1993 observations. Mon. Weather Rev., 124, 1211-1224

A two-layer quasi-geostrophic model of summer trough formation in the Australian subtropical easterlies. J. Atmos. Sci., 41, $807-818$

A two-dimensional simulation of the Iberian summer thermal low. Mon. Weather Rev., 121, 2740-2756

The generation of the morning glory. J. Atmos. Sci., 61, 13601376

Prefrontal troughs over southern Australia. Part I: A climatology. Weather and Forecasting, 5, 22-31

Prefrontal troughs over southern Australia. Part II: A case study of frontogenesis. Weather and Forecasting, 5, 32-46

The Iberian Peninsula thermal low. Q. J. R. Meteorol. Soc., 129, $1491-1511$

The satellite-determined thermal structure of heat lows during Indian south-west monsoon season. Adv. Space Res., 5, $57-60$

'An investigation of the summer lows over the Qinghai-Xizang plateau'. Pp. 369-386 in Proceedings of the international symposium on the Qinghai-Xizang plateau and mountain meteorology, 20-24 March 1984, Beijing, China. American Meteorological Society 1986, 45 Beacon Street, Boston MA02108-3693, USA

A simple model of the Australian west coast trough. Mon. Weather Rev., 120, 2042-2055

Real-time forecasting of the Western Australian summertime trough: Evaluation of a new regional model. Weather and Forecasting, 9, 371-383 
Mellor, G. and Yamada, T.

Miller, M. J. and Pearce, R. P.

Morris, R. M.

Noonan, J. A. and Smith, R. K.

Pedgley, D. E.

Portela, A. and Castro, M.

Preissler, M., Reeder, M. J. and Smith, R. K.

Puri, K., Dietachmayer, G. S., Mills, G. A., Davidson, N. E., Bowen, R. A. and Logan, L. W.

Rácz, Z. and Smith, R. K.

Reeder, M. J., Smith, R. K., Deslandes, R., Tapper, N. and Mills, G. A.

Rowson, D. R. and Colucci, S. J.

Serrano, S., Garcia, J. A., Mateos, V. L., Cancillo, M. L. and Garrido, J.

Smith, E. A.

Smith, R. K. and Ridley, R. N.

Smith, R. K., Reeder, M. J., Tapper, N. J. and

Christie, D. R.

Thorncroft, C. D. and Flocas, H. A. 1997
1974 Hierarchy of turbulence closure models for planetary boundary layer. J. Atmos. Sci., 31, 1791-1806

1982 Development of a turbulent closure model for geophysical problems. Rev. Geophys. Space Phys., 31, 1791-1806

1974 A three-dimensional primitive equation model of cumulonimbus convection. Q. J. R. Meteorol. Soc., 100, 133-154

1986 The Spanish plume-testing the forecaster's nerve. Meteorol. Mag., 115, 349-357

1986 Sea-breeze circulations over Cape York Peninsula and the generation of Gulf of Carpentaria cloud line disturbances. J. Atmos. Sci., 43, 1679-1693

1972 Desert depressions over north-east Africa. Meteorol. Mag., 101, 228-244

1996 Summer thermal lows in the Iberian peninsula: A threedimensional simulation. Q. J. R. Meteorol. Soc., 122, 1-22

2002 A case study of a heat low over central Australia. Aust. Meteorol. Mag., 51, 155-163

1998 The new BMRC Limited Area Prediction System, LAPS. Aust. Meteorol. Mag., 47, 203-223

1999 The dynamics of heat lows. Q. J. R. Meteorol. Soc., 125, 225-252

2000 Subtropical fronts observed during the 1996 Central Australian Cold Fronts Experiment. Aust. Meteorol. Mag., 49, 181-200

1992 Synoptic climatology of thermal low-pressure systems over southwestern North America. Int. J. Climatol., 12, 529-545

1999 Monthly modes of variation of precipitation over the Iberian Peninsula. J. Climate, 12, 2894-2919

1986a The structure of the Arabian heat low. Part I: Surface energy budget. Mon. Weather Rev., 114, 1067-1083

1986b The structure of the Arabian heat low. Part II: Bulk tropospheric heat budget and implications. Mon. Weather Rev., 114, 10841102

1990 Subtropical continental cold fronts. Aust. Meteorol. Mag., 38, 191-199

1995 Central Australian cold fronts. Mon. Weather Rev., 123, 16-38

A case study of Saharan cyclogenesis. Mon. Weather Rev., 125, 1147-1165 